\title{
Effectiveness of Autologous Fat Graft in Treating Fecal Incontinence
}

\author{
Hyeonseok Jeong, Sung Hwan Hwang, Hyoung Rae Kim, Kil O Ryu, Jiyong Lim, Hye Mi Yu, Jihoon Yoon, \\ Chee Young Kim, Kwang-Yong Jeong, Young Jae Jung, In Seob Jeong, Young Gil Choi \\ Department of Surgery, Busan Hangun Hospital, Busan, Korea
}

Purpose: The most common risk factor for fecal incontinence (FI) is obstetric injury. FI affects $1.4 \%-18 \%$ of adults. Most patients are unaware when they are young, when symptoms appear suddenly and worsen with aging. Autologous fat graft is widely used in cosmetic surgical field and may substitute for injectable bulky agents in treating FI. Authors have done fat graft for past several years. This article reports the effectiveness of the fat graft in treating FI and discusses satisfaction with the procedure.

Methods: Fat was harvested from both lateral thighs using 10-mL Luer-loc syringe. Pure fat was extracted from harvests and mixed with fat, oil, and tumescent through refinement. Fats were injected into upper border of posterior ano-rectal ring, submucosa of anal canal and intersphincteric space. Thirty-five patients with FI were treated with this method from July 2016 to February 2017 in Busan Hangun Hospital. They were 13 male (mean age, 60.8 years) and 22 female patients (mean age, 63.3 years). The Wexner score was checked before procedure. We evaluated outcome in outpatients by asking the patients. For 19 patients we checked the Wexner score after procedure.

Results: Symptom improved in 29 (82.9\%), and not improved in 6 (17.1\%). In 2 of 6 patients, they felt better than before procedure, although not satisfied. No improvement in 4 . Mean Wexner score was 9.7 before procedure. There were no serious complications such as inflammation or fat embolism.

Conclusion: Autologous fat graft can be an effective alternative treatment for FI. It is safe and easy to perform, and cost effective.

Keywords: Fecal incontinence; Autologous fat graft; Bulking form agent injection

\section{INTRODUCTION}

Fecal incontinence is defined as the inability to control the passage of gas, solid stool, or liquid stool over a 1-month period [1]. Patients with fecal incontinence often lose their sense of self-esteem due to the embarrassment of the foul smell and involuntary fecal discharge. Therefore, most patients are embarrassed with

Received: July 11, 2018 - Accepted: September 15, 2018

Correspondence to: Sung Hwan Hwang, M.D.

Department of Surgery, Busan Hangun Hospital, 1 Chungnyeol-daero

348beon-gil, Dongnae-gu, Busan 47889, Korea

Tel: +82-51-580-2824, Fax: +82-51-580-2753, E-mail: hwancin@hanmail.net ORCID code: https://orcid.org/0000-0003-0429-7086

(C) 2019 The Korean Society of Coloproctology

This is an open-access article distributed under the terms of the Creative Commons Attribution NonCommercial License (http://creativecommons.org/licenses/by-nc/4.0) which permits unrestricted noncommercial use, distribution, and reproduction in any medium, provided the original work is properly cited. their symptoms and do not talk about it with family members or friends. As the patients are reluctant to go out or stay away from their families, their quality of life deteriorates. There are many cases of self-isolation without social activities. And if patients develop mental health problems such as depression, it might lead to social problems due to extreme choices such as suicide $[2,3]$. The prevalence of fecal incontinence may vary depending on survey methods but usually accounts for $1.4 \%-18 \%$ of the total population [4-7]. In the Mature Women's health study using Nelson data, more than $20 \%$ of women aged 45 years or over experienced fecal incontinence at least once a year, and 9.5\% experienced it more than once a month [8]. Considering the tendency of patients who are reluctant to go to hospital even though they have fecal incontinence symptoms, it is estimated that more people might have fecal incontinence symptoms than those confirmed by the survey [9].

The treatment of fecal incontinence is determined in consider- 
ation of the causes and contribution factors of the pathology [10, 11]. Conservative therapy is initiated by intestinal motility control, medication such as antidiarrheal and bulk laxatives, biofeedback, or magnetic stimulation. If conservative treatments do not improve symptoms, surgical treatment is considered. Previous surgical treatments were invasive but did not show sufficiently good results [12].

The currently representative surgical treatment is sphincter repair. If symptoms do not improve, various methods are introduced. Injectable bulky agent or radiofrequency remodeling (SECCA, Curon Medical, Freemont, CA, USA) has been introduced as a method to reinforce sphincter function. In Europe, a method of inserting a shape memory substance between sphincters (Sphinkeeper) has been introduced. To replace the sphincter muscle, muscle transposition is performed or artificial bowel sphincter is implanted. There are several ways to stimulate the nerves: sacral neuromodulation and posterior tibial nerve stimulation. If these methods fail to solve the problem, an intestinal tract may be installed [13].

The authors are treating the patients according to their own guidelines on conservative treatments and surgical treatments. Recently, autologous fat graft, which is widely used in cosmetic surgery, has been applied to the treatment of fecal incontinence and showed a significant symptom improvement. This study was conducted to evaluate the efficacy and safety of autologous fat transplantation in the treatment of fecal incontinence. The study method is a retrospective study that is done through the review of medical records. This study was approved by the Public Institutional Review Board (IRB) designated by the Republic of Korea's Ministry of Health and Welfare and was exempted from an informed consent requirement by the IRB.

\section{METHODS}

\section{Subjects}

Among the patients who underwent autologous fat graft from July 2016 to February 2017, this study selected 35 patients whose postoperative progress was observed for at least 6 months and reviewed their medical records. Fecal incontinence was classified into three types according to symptoms [14]: an involuntary loss of rectal content; an urgency, in which a patient has a sudden compelling need to defecate that is difficult to delay; and a seepage, in which a patient experiences fecal leakage onto underwear after perianal cleaning following defecation [14]. Based on the patients' medical history and physical examination, the surgical history of the anus rectum as well as the history of treatment of fecal incontinence was examined. Preoperative endoscopy, anal manometry, anal ultrasonography, and cinedefecography were performed. The Wexner score was used to confirm the severity of fecal incontinence. The patients were recommended to be hospitalized for one day after the procedure to observe the complications such as bleeding and fat leak. They visited the outpatient ward at
2 weeks, 4 weeks, 2 months, and 5 months after the procedure for testing of complications. In the 2 months after the procedure, the surgery results were evaluated by questioning the patients at the outpatient ward. It was concluded that it was effective when the patients said that the symptoms of stool incontinence were reduced by more than $50 \%$ compared to before the procedure. Of the 35 patients, 19 patients were tested to evaluate the Wexner scores after the procedure. In some patients, cinedefecography and anal manometry test were performed 2 to 3 months after the procedure to compare the anorectal pressures and the anatomical change in the anorectum with before the procedure. The IBM SPSS Statistics ver. 19.0 (IBM Co., Armonk, NY, USA) was used for statistical analysis. Patients' sex, age, symptom duration, type and severity of fecal incontinence, degree of incontinence, and past anorectal surgery were examined through the review of the medical records. The mean anorectal pressure before the procedure, the amount of autologous fat graft at the time of operation, the change in anal rectal angle before and after the procedure, the improvement of fecal incontinence after the operation, and postoperative complications were confirmed.

\section{Procedure}

Autologous fat transplantation is performed in the following order: harvesting, refinement, and injection \& implantation of fat. The procedure was performed in the Prone Jack-knife position under spinal anesthesia. Fat collection was performed in both thighs and buttocks, but when it was impossible to collect it from the thighs, it was collected from the abdomen instead [15]. After an incision big enough for a collection needle to enter was done on the wrinkled skin of the posterosuperior area of the thighs using the surgical blade No. 11, Tumescent solution was injected to be evenly spread into the collection site [16]. The cannula for fat collection (Fig. 1A) connected to a 10-mL lure-lock syringe (Fig. 1B) was rapidly moved back and forth through the incision site to collect fat (Fig. 2). A total of 40- to 60-mL tissues were collected using a 10-mL syringe. Inside the collection syringe, there was a mixture of Tumescent solution, blood, plasma, oil, and fat (Fig. $3 \mathrm{~A}$ ). The syringe containing the collected tissue was placed in a centrifuge (Tabletop Low Speed Centrifuge TDZ4-WS, Luxiangyi, China) to refine the pure fat. The centrifuge was operated for 3 minutes at a speed of 3,000 rpm (Fig. 3B). Please note that if the speed is too fast or if the separation is done for too long, the fat may be broken and therefore, the implantation may fail after the fat graft [17]. The refined fat was transferred with a 1cc lure-lock syringe connected to the cannula (Fig. 4) and injected through a passage, incised with the 11th surgical blade, 2 knuckles away from the back of the anal canal. Fat injection was performed in three steps. First, while a finger was inserted into the anus and a cushion filled with fat was felt, about $10 \mathrm{~mL}$ was injected into the submucosal layer of the upper posterior area in a crescent shape in the direction of 3-4 oclock and 8-9 oclock. The procedure was being done while feeling the cushion of the anus being inflated by 


\section{Annals of Effectiveness of Autologous Fat Graft in Treating Fecal Incontinence \\ Coloproctology Hyeonseok Jeong, et al.}
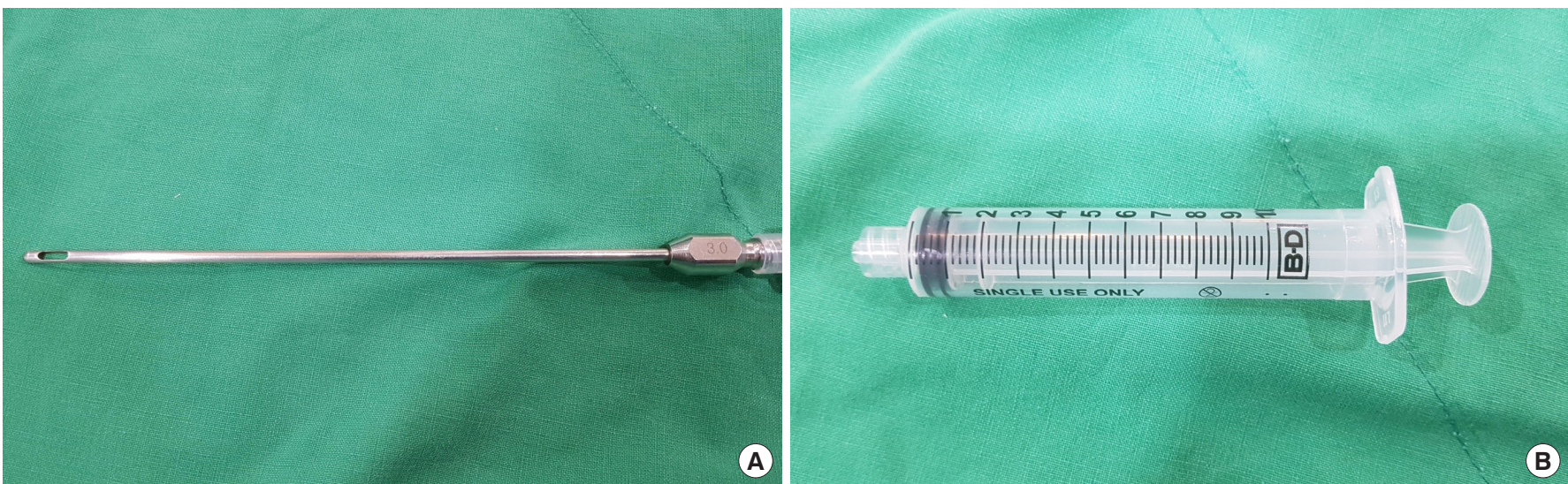

Fig. 1. (A) Cannula for liposuction. (B) 10-mL lure-lock syringe.

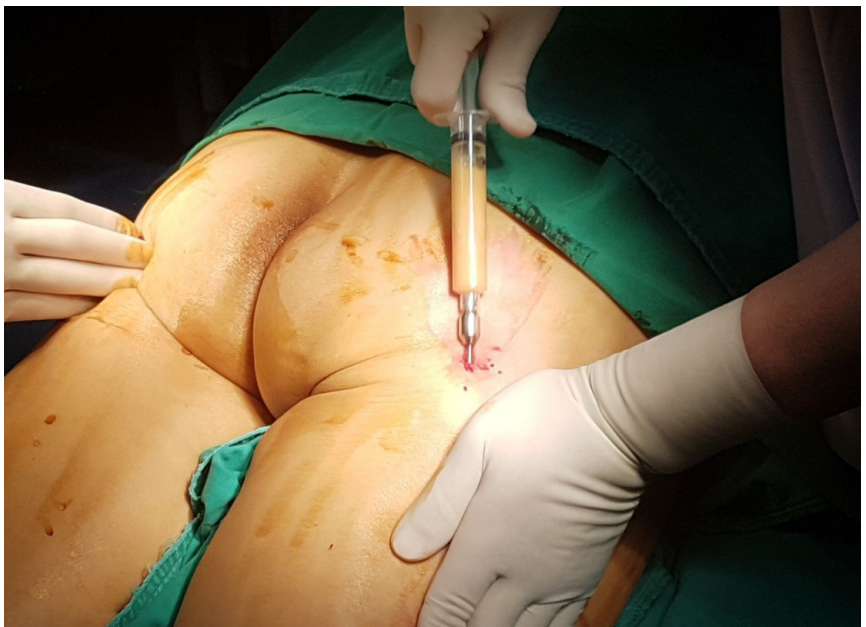

Fig. 2. Liposuction using cannula and 10-mL lure-lock syringe.
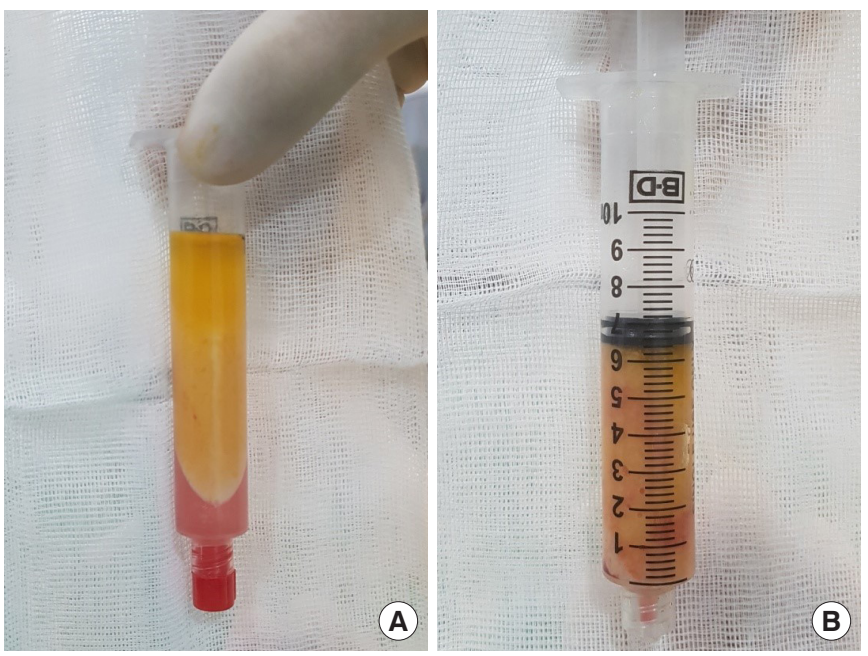

Fig. 3. (A) Blood, plasma, tumescent fluid, fat tissue, and oil. (B) Fat tissue after refinement.

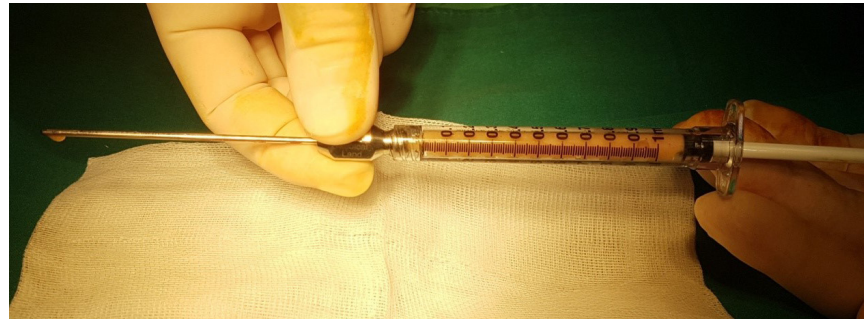

Fig. 4. Cannula and 1-mL lure-lock syringe connected for fat transplantation.

the injection of fat with the fingertip. At this point, it was necessary to ensure that the fat was spread evenly, so that the injected fat was not pushed to one side and did not form a lump (Fig. 5). Next, fat was injected into the superior area of the anus rectal ring in the same way. Care was taken to make sure that the fat was not pushed upward into the large space of the rectal mucosal layer, which is located in the superior area of the anus rectal ring. When about 20 to $25 \mathrm{~mL}$ of fat was injected, a sufficient inflation could be felt in the posterior area of the anus rectal ring.

\section{RESULTS}

Among the patients who underwent autologous fat transplantation from July 2016 to February 2017, 35 patients whose postoperative progress was observed for at least 6 months were selected as the subjects of this study. There were 13 male subjects whose age ranged from 32 years old to 79 years old, and their mean age was estimated at 60.8 years old. There were 22 female subjects whose age ranged from 40 years old to 75 years old, and their mean age was estimated at 63.3 years old. There were 31 patients who had a history of anorectal surgery. Four patients had a history of colorectal cancer surgery, while 27 patients had a history of anal surgery. The mean duration of symptoms was 7.9 months. The Wexner scores that were measured before surgery ranged 


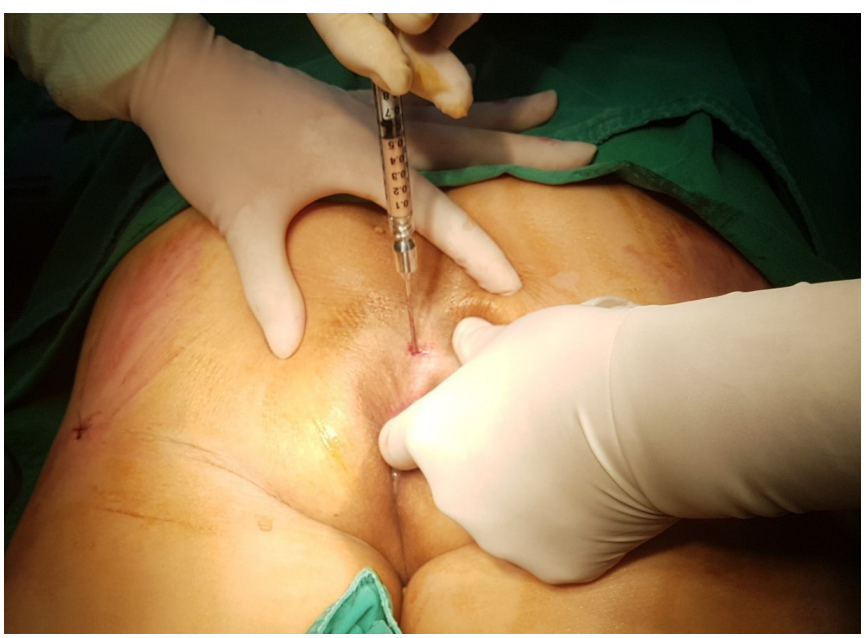

Fig. 5. Autologous fat inserted into incision site by cannula and 1-mL lure-lock syringe.

from 6 to 16 points, with a mean score of 9.7 points. Thirteen patients (37.2\%) belonged to the involuntary loss type; 8 patients (22.9\%) belonged to the seepage type; 6 patients (17.1\%) belonged to the urgency type. Five patients (14.3\%) had involuntary loss accompanied by urgency, while 3 patients $(8.6 \%)$ had seepage accompanied by urgency. Twenty-two patients had a history of stool incontinence surgery. Thirteen patients had a history of the Thiersch operation. Seven patients had a history of sphincter repair. Two patients had a history of Levatorplasty (Table 1). According to the results of the preoperative anal manometry, the maximum mean resting pressure was $35.6 \mathrm{mmHg}$. The amount of the injected fat ranged from a minimum of $14 \mathrm{~mL}$ to a maximum of $35 \mathrm{~mL}$, with the mean amount of $25 \mathrm{~mL}$.

The condition of the patients was checked and the results of the procedure were evaluated at 2 weeks, 4 weeks, 2 months, and 5 months after the procedure. At 2 months after the procedure, the patients were asked whether their symptoms were reduced by more than $50 \%$ compared to before the procedure. It was judged as improvement if the symptoms of fecal incontinence were reduced by more than $50 \%$. A total of 29 patients $(82.9 \%$ ) showed a significant symptom improvement. Two patients (5.7\%) had a mild but unsatisfactory symptom improvement, while 4 patients (11.4\%) said that the results were below expectations. No complications including bleeding, infection, abscess, leakage, migration of transplanted fat, or fat embolism were found (Table 2).

Of the 35 patients, 19 patients underwent a measurement of Wexner scores after the procedure. The results were compared with before the procedure. In case of Wexner scores before surgery, the scores ranged from 6 points to 15 points, with the mean value of 9.5 points. If we look at the Wexner scores after surgery, the scores ranged from 0 to 12 points, with the mean value of 4.7 points. The scores before and after surgery were compared through the paired t-test, and the results showed that the Wexner
Table 1. Demographics and clinical characteristics of patients with fecal incontinence who were treated by autologous fat graft

\begin{tabular}{lc}
\hline Clinical characteristic & Value \\
\hline Sex, male : female & $13: 22$ \\
Age (yr) & \\
Male & $60.8 \pm 12.2(32-79)$ \\
Female & $63.3 \pm 7.5(40-75)$ \\
Fecal incontinence type & \\
Involuntray loss of stool & $13(37.2)$ \\
Seepage & $8(22.9)$ \\
Urgency & $6(17.1)$ \\
Urgency, involuntary loss of stool & $5(14.3)$ \\
Urgency, seppage & $3(8.6)$ \\
Past rectal anal operation history (No. of cases) & $31(88.5)$ \\
Previous fecal incontinence operation history & $22(62.8)$ \\
(No. of cases) & \\
Symptom onset (mo) & $8.0 \pm 7.7(1-30)$ \\
Previous procedure Wexner score & $9.7 \pm 3.1(6-16)$ \\
\hline
\end{tabular}

Values are presented as mean \pm standard deviation (range) or number (\%).

Table 2. Surgical outcomes and complications

\begin{tabular}{lc}
\hline Surgical characteristic & Value \\
\hline Fat injection amount (mL) & $25.1 \pm 5.7(14-35)$ \\
Post operation outcome (No. of cases) & $29(82.9)$ \\
Symptom improved & $2(5.7)$ \\
Symptom improved (not over 50\%) & $4(11.4)$ \\
Symptom not improved & \\
Complications (No. of cases) & $1(2.8)$ \\
Tenesmus & $0(0)$ \\
Bleeding & $0(0)$ \\
Material leakage \& shifting & $0(0)$ \\
Infection \& abscess & $0(0)$ \\
Inflammation & $0(0)$ \\
Fat embolism &
\end{tabular}

Values are presented as mean \pm standard deviation (range) or number (\%).

scores after surgery showed a statistically significant decrease compared with before the surgery $(\mathrm{P}<0.001)$.

Among the patients who showed symptom improvement, 18 patients underwent anal manometry, and a comparative analysis of the maximum mean resting pressure before and after the procedure was carried out. The maximum mean resting pressure before the procedure ranged from 15.7 to $89.7 \mathrm{mmHg}$, with the mean value of $36.2 \mathrm{mmHg}$. The maximum mean resting pressure after the procedure ranged from 19.2 to $69.0 \mathrm{mmHg}$, with the mean value of $34.6 \mathrm{mmHg}$. The maximum mean pressure before 
Table 3. Comparison of Wexner score, maximum mean resting pressure, and rectoanal angle between pre- and postprocedure

\begin{tabular}{lcrr}
\hline Variable & Preprocedure & Postprocedure & P-value \\
\hline Wexner score $(\mathrm{n}=19)$ & $9.5 \pm 3.3(6-15)$ & $4.7 \pm 3.3(0-12)$ & $<0.001$ \\
MMRP $(\mathrm{mmHg})(\mathrm{n}=18)$ & $36.2 \pm 17.6(15.7-89.7)$ & $34.6 \pm 19.2(19.2-69.0)$ & 0.845 \\
Rectoanal angle $\left(^{\circ}\right)(\mathrm{n}=18)$ & $126.4 \pm 13.2(107-154)$ & $116.2 \pm 11.2(98-135)$ & $<0.001$ \\
\hline
\end{tabular}

Values are presented as mean \pm standard deviation (range).

MMRP, maximum mean resting pressure.

and after the procedure was analyzed through the Wilcoxon signed-rank test, and the results did not show any statistically significant difference between before and after the procedure $(\mathrm{P}=$ 0.845). Compared with before the procedure, there was no evidence of consistent changes in anorectal pressure between before and after the procedure. Among the patients who showed symptom improvement, 18 patients underwent cinedefecography, and their anorectal angle before the procedure was compared with the one after the procedure. Among them, 15 patients showed that the anorectal angle after the procedure was changed to an acute angle compared with before the procedure. The decreased magnitude of the angle ranged from a minimum of $1^{\circ}$ to a maximum of $30^{\circ}$, and the decreasing rate of the angle ranged from a minimum of $0.4 \%$ to a maximum of $20 \%$. Three patients did not show any change in anorectal angle. In the case of anorectal angle measured before the procedure by cinedefecography, the angle ranged from $107^{\circ}$ to $154^{\circ}$, with a mean value of $126.4^{\circ}$. The anorectal angle measured after the procedure by cinedefecography ranged from $98^{\circ}$ to $135^{\circ}$, with a mean value of $116.4^{\circ}$. The anorectal angles before and after surgery were compared through the paired t-test, and the results showed a statistically significant decrease in the anorectal angle after the procedure $(\mathrm{P}<0.001)$ (Table 3$)$.

\section{DISCUSSION}

The physiology around the anus rectum that affects fecal continence can be divided into 3 categories. The first is the role of sphincters around the anus and pelvis and of the cushion of the anal canal, which is represented by the sphincter barrier. Sphincter and anal cushion maintain the normal tension of the anal canal during the resting period to hold stool. However, when passing stool, they become relaxed and relieve the anorectal angle to induce a smooth passage of stool. Studies have been conducted in a relatively detailed manner on the role of sphincters, including puborectalis muscles in forming the anal high pressure zone and in holding stool. Most of the studies agree on the role of the anal high pressure zone, anorectal angle, and anal cushion in holding stool and facilitating a smooth passage of stool [18-21].

The second is the defecation sense and reflex mechanism of a normal pelvis, rectum, and anal canal, which is represented by the defecation mechanism. There are normal reflex mechanisms in the Sigmoid colon, rectum, anal sphincter, and anorectal ring. In the case of the inner sphincter, it always maintains the state of maximum contraction. If gas is inflated into the rectum, an internal sphincteric relaxation, called the 'sampling reflex,' can be observed. It is possible to know the presence of the reflex mechanism of the inner sphincter, which is called the recto-anal inhibitory reflex [20-22]. It is because of the pelvic floor receptor that one can emit gas while holding stool. It is because pelvic muscles can distinguish between the pressure of gas and of the solid content [23]. The external sphincter maintains the tonically active condition during the resting state but loses pressure during the sleeping state. At this time, however, the pressure in the rectum also drops in order to hold stool. The role of the exogenous sphincter is very important for stool continence in case of coughing and abdominal pressure increases [21,24].

The third is the reserve capacity of the rectum and the normal rectal distensibility, which is represented by rectal compliance. One can feel the rectum being filled up with solid content from 10 to $300 \mathrm{~mL}$, in which one starts to feel urgency. The rectal compliance is a change in pressure caused by an increase in the unit volume. A regular and constant rectal contraction results from rectal swelling. Sensory impairment in the rectum can cause an indiscriminate rectal swelling and increase rectal contractility, which in turn interrupts a normal rectal swelling. Even when the pressure in the rectum increases, rectal tolerance helps one hold stool for a period of time until the rectum becomes full of solid content, and humans are trained to tolerate the stool sensation. However, if the rectum is filled up with feces at too excessive a level to hold stool, one should eventually pass stool. If patients have rectal prolapse or rectal incontinence accompanied by anorectal sphincter damage, they can have persistent intrinsic sphincter suppression even in case of a small amount of rectal swelling. This is because the mass of rectal prolapse itself is perceived as stool even when there is no actual stool $[20,21,25]$.

There are 3 types of surgical treatments of fecal incontinence. The first is the correction of the sphincter barrier. This includes sphincter repair, sphincteroplasty, and muscle transposition. The second is the correction of pelvic floor and anal outlet orifice, which includes postanal repair or artificial anal sphincter, puborectal sling, and injectable biomaterial. The third is the functional rehabilitation by nerve stimulation, which includes posterior tibial nerve stimulation and sacral nerve stimulation [26]. In 1993, Shafik, an Egyptian surgeon, injected polytetrafluoroethylene into the anal submucosa of 11 patients [27]. After that, there has been an increased interest in the use of injectable biomaterials 
for the augmentation of the anal canal, and various materials including autologous fat, glutaraldehyde cross-linked collagen, carbon-coated beads (Durasphere), stabilized hyaluronic acid, and porcine dermal collagen matrix have been used as bulking agents. In 1995, Shafik [28] performed autologous fat transplantation in 14 patients with rectal incontinence and showed a $100 \%$ success rate according to observations at 2 to 3 months after the procedure. After that, Bernardi et al. [29] and Cestaro et al. [30] have reported on autologous fat transplantation for patients with rectal incontinence. Their study showed a decrease in the frequency of fecal incontinence in $80 \%$ of the patients. These results suggest that autologous fat transplantation can be an effective treatment of fecal incontinence.

Through the present study, it was confirmed that autologous fat transplantation had a significant effect on the treatment of fecal incontinence. We also inferred the possible effects of autologous fat transplantation on the treatment of fecal incontinence. The first possible effect is the recovery of the anorectal angle. Many patients with fecal incontinence have an enlarged anorectal angle [21], and when the anorectal angel before surgery was compared with the one after surgery, $80 \%$ of the patients showed a decrease in the anorectal angle. The second possible effect is the creation and relocation of an anal cushion. In this study, fat was injected into the posterior and lateral side of the anal canal. If fat is injected into the anterior of the anus, fat embolism might occur. Unlike small-sized needles used for cosmetic purposes, large needles (18 $\mathrm{G}$ or larger) are used for anal injection, and the possibility of fat embolism is thus very low. Even so, if fat is anatomically injected into the area where there are many large blood vessels around the anus, one must take care to ensure that fat is not injected into a blood vessel. The third possible effect is a fibrous change that occurs when fat is seated. It is expected that fibrous changes can reinforce the anorectal ring in the posterior side of the anal canal. If a soft wound contraction occurs due to the nature of the fat, it is expected to reinforce the puborectal sling. This may be considered as one of the most innovative treatments of fecal incontinence. The fourth possible effect is the lengthening and narrowing of the anal canal. Although this study, which lacks a long-term follow-up and investigation, cannot prove or verify all of these assumptions, it is worth considering the results of this study when setting a direction for future study.

The authors believe that when we classify autologous fat transplantation as an injectable biomaterial method, it meets the requirements of an ideal biomaterial. Although it is already widely accepted as common sense, Vaizey and Kamm [31] have suggested the conditions of the ideal injectable biomaterial: Injectable biomaterials should be biologically compatible with the human body and be free of allergic reactions or immunological rejection. It should also be easy to inject, free from migration between tissues, and not cause inflammatory reactions. A variety of biomaterials have been researched and developed to find one that satisfies all these conditions [26]. Since the report of the case in which a patient died of pulmonary embolism after a fat graft to treat urinary incontinence $[32,33]$, the autologous fat transplant has escaped people's attention. However, as the above-mentioned case was periurethral injection, it is difficult to do a simple comparison. In this study, there were no serious complications such as hemorrhaging, infection, inflammation, abscess, or fat embolism.

Questions have been raised about the long-term effects of autologous fat transplantation. It is true that there are cases in which transplanted fat is not correctly implanted, and there is concern that the size of the fat will decrease after the procedure. These problems can be solved by improving the outcome of transplantation through better surgical technology and accumulation of experience. In addition, these problems should be overcome with long-term follow-up observations and a careful analysis of the patients. As for using the patient's own fat, it has been confirmed that other bulking agents did not last as long and required reinjection after a certain period of time [34]. Autologous fat transplantation is easy to perform and less invasive because it is a simple task of pulling fat with a syringe and moving it to another part of the body. It is thus relatively easy to implement with simple equipment. Fat transplantation is already a common practice in the field of cosmetic surgery, and it is a procedure for which it is easy to predict the results and prognosis. Because it uses a patient's own fat, it does not cause foreign body reaction or inflammation. In addition, the possibility of complications including fat embolism is less of a concern because only a small amount of fat is injected and because the surrounding area of the target injection spot does not have big blood vessels. It also has great advantages in terms of cost and can be repeatedly administered.

In Cochrane's review, which studied the previously released literature on biomaterial injection, only one large randomized controlled trial (RCT) showed that more than half of the subjects had a short-term effect, and the remaining studies failed to provide reliable data that could prove the effect because of the limited number of confirmed studies and methodological limitations. However, the results reported in this paper confirmed the shortterm improvements from the autologous fat transplantation [35]. The present study is a retrospective research, which has the limitations of a small number of subjects and a short follow-up period, but given the socio-psychological situation of patients as described above, it is difficult to conduct a long-term research. However, as the perception of fecal incontinence changes, an extensive RCT study can eventually be carried out on a large number of subjects to verify the effectiveness of autologous fat transplantation, once it is clearly recognized that fat transplantation does not pose a significant risk to patients.

In conclusion, autologous fat graft is safe and is a less invasive treatment for fecal incontinence than other surgical procedures. Because there are many sites to collect fat, the procedure can be repeatedly done. Complications are unlikely to happen if the underlying principles for the procedure are followed. It does not require large facilities or equipment. As the procedure is simple and 
does not cause a big wound, patients can return to their daily life quickly. There are high expectations about the volume effect of autologous fat graft due to changes in the anal canal, and patients' short-term satisfaction of the procedure is also high. Based on these advantages, autologous fat transplantation can be considered a viable surgical procedure to treat fecal incontinence.

\section{CONFLICT OF INTEREST}

No potential conflict of interest relevant to this article was reported.

\section{REFERENCES}

1. Whitehead WE, Wald A, Norton NJ. Treatment options for fecal incontinence. Dis Colon Rectum 2001;44:131-42.

2. Mavrantonis C, Wexner SD. A clinical approach to fecal incontinence. J Clin Gastroenterol 1998;27:108-21.

3. Miner PB Jr. Economic and personal impact of fecal and urinary incontinence. Gastroenterology 2004;126(1 Suppl 1):S8-13.

4. Ditah I, Devaki P, Luma HN, Ditah C, Njei B, Jaiyeoba C, et al. Prevalence, trends, and risk factors for fecal incontinence in United States adults, 2005-2010. Clin Gastroenterol Hepatol 2014; 12:636-43.e1-2.

5. Goode PS, Burgio KL, Halli AD, Jones RW, Richter HE, Redden DT, et al. Prevalence and correlates of fecal incontinence in community-dwelling older adults. J Am Geriatr Soc 2005;53:629-35.

6. Markland AD, Goode PS, Burgio KL, Redden DT, Richter HE, Sawyer $\mathrm{P}$, et al. Incidence and risk factors for fecal incontinence in black and white older adults: a population-based study. J Am Geriatr Soc 2010;58:1341-6.

7. Whitehead WE, Borrud L, Goode PS, Meikle S, Mueller ER, Tuteja $\mathrm{A}$, et al. Fecal incontinence in US adults: epidemiology and risk factors. Gastroenterology 2009;137:512-7, 517.e1-2.

8. Nelson RL. Epidemiology of fecal incontinence. Gastroenterology 2004;126(1 Suppl 1):S3-7.

9. Brown HW, Wexner SD, Segall MM, Brezoczky KL, Lukacz ES. Accidental bowel leakage in the mature women's health study: prevalence and predictors. Int J Clin Pract 2012;66:1101-8.

10. Tan JJ, Chan M, Tjandra JJ. Evolving therapy for fecal incontinence. Dis Colon Rectum 2007;50:1950-67.

11. Al-Abed YA, Ayers J, Ayantunde A, Praveen BV. Safety and efficacy of permacol injection in the treatment of fecal incontinence. Ann Coloproctol 2016;32:73-8.

12. Maslekar S, Smith K, Harji D, Griffiths B, Sagar PM. Injectable collagen for the treatment of fecal incontinence: long-term results. Dis Colon Rectum 2013;56:354-9.

13. Paquette IM, Varma MG, Kaiser AM, Steele SR, Rafferty JF. The American Society of Colon and Rectal Surgeons' Clinical Practice Guideline for the treatment of fecal incontinence. Dis Colon Rectum 2015;58:623-36.

14. Rao SS; American College of Gastroenterology Practice Parame- ters Committee. Diagnosis and management of fecal incontinence. American College of Gastroenterology Practice Parameters Committee. Am J Gastroenterol 2004;99:1585-604.

15. Pereira LH, Radwanski HN. Fat grafting of the buttocks and lower limbs. Aesthetic Plast Surg 1996;20:409-16.

16. Klein JA. Tumescent formulation. In: Klein JA, De Jong RH, Massari E, editors. Tumescent technique: tumescent anesthesia \& microcannular liposuction. St. Louis (MO): Mosby; 2000. p. 187-95.

17. Fulton JE, Suarez M, Silverton K, Barnes T. Small volume fat transfer. Dermatol Surg 1998;24:857-65.

18. Kerremans R. Morphological and physiological aspects of anal continence and defaecation. Bruxelles: Arscia; 1969.

19. Monges H, Salducci J, Naudy B, Ranieri F, Gonella J, Bouvier M. The electrical activity of the internal anal sphincter: a comparative study in man and in cats. In: Christensen J, editor. Gastrointestinal motility. New York: Raven Press; 1980. p. 487-93.

20. Cuomo R, Bottiglieri ME, Budillon G. Pathophysiology and clinical approach to fecal incontinence. In: Lehur PA, Weiss E, Cuomo $R$, Romano G, editors. Diagnosis and treatment of fecal incontinence. New York: Idelson-Gnocchi Pub; 2000. p. 20-37.

21. Kang SB. Fecal incontinence. In: Park JG, editor. Coloproctology. 4th ed. Seoul: Ilchokak; 2012. p. 329-67.

22. Miller R, Lewis GT, Bartolo DC, Cervero F, Mortensen NJ. Sensory discrimination and dynamic activity in the anorectum: evidence using a new ambulatory technique. Br J Surg 1988;75:10037.

23. Lagoidet J, Berrod J, Duché M, Bron M. Incontinence anorectale. Diagnostic, explorations, traitement. Encycl Méd Chir, Gastroentérologie, 9-087-G-20, 1999.

24. Johnson MA, Polgar J, Weightman D, Appleton D. Data on the distribution of fibre types in thirty-six human muscles. An autopsy study. J Neurol Sci 1973;18:111-29.

25. Maxwell PR, Heriot AG, Davies DC, Kumar D. Anorectal sensation and continence. Scand J Gastroenterol 1999;34:113-6.

26. Madoff R, Laurberg S, Lehur P, Matzel K, Mellgren A, Mimura T, et al. Surgery for faecal incontinence. In: Abrams P, Cardozo L, Khoury S, Wein A, editors. Incontinence. 5th ed. Paris: International Consultation on Urological Diseases and European Association of Urology; 2013. p. 1487-526.

27. Shafik A. Polytetrafluoroethylene injection for the treatment of partial fecal incontinence. Int Surg 1993;78:159-61.

28. Shafik A. Perianal injection of autologous fat for treatment of sphincteric incontinence. Dis Colon Rectum 1995;38:583-7.

29. Bernardi C, Favetta U, Pescatori M. Autologous fat injection for treatment of fecal incontinence: manometric and echographic assessment. Plast Reconstr Surg 1998;102:1626-8.

30. Cestaro G, De Rosa M, Massa S, Amato B, Gentile M. Intersphincteric anal lipofilling with micro-fragmented fat tissue for the treatment of faecal incontinence: preliminary results of three patients. Wideochir Inne Tech Maloinwazyjne 2015;10:337-41.

31. Vaizey CJ, Kamm MA. Injectable bulking agents for treating faecal incontinence. Br J Surg 2005;92:521-7. 
32. Currie I, Drutz HP, Deck J, Oxorn D. Adipose tissue and lipid droplet embolism following periurethral injection of autologous fat: case report and review of the literature. Int Urogynecol J Pelvic Floor Dysfunct 1997;8:377-80.

33. Sweat SD, Lightner DJ. Complications of sterile abscess formation and pulmonary embolism following periurethral bulking agents.
J Urol 1999;161:93-6.

34. Lee DH. Role of permacol injection in the treatment of patients with fecal incontinence. Ann Coloproctol 2016;32:49-50.

35. Maeda Y, Laurberg S, Norton C. Perianal injectable bulking agents as treatment for faecal incontinence in adults. Cochrane Database Syst Rev 2013;(2):CD007959. 